\title{
Simucase: Embrace the Power of Simulation-Based Learning
}

DOI: https://doi.org/10.30707/TLCSD4.3/BWHV6573

Follow this and additional works at: https://ir.library.illinoisstate.edu/tlcsd

We are pleased to have Simucase sponsor this very special issue. Please note that while Simucase offers simulation materials for communication sciences and disorders education, they had no editorial input regarding the contents of this issue. This issue was produced with complete autonomy by the Editorial Board of Teaching and Learning in Communication Sciences \& Disorders.

\section{Recommended Citation}

(2020) "Simucase: Embrace the Power of Simulation-Based Learning," Teaching and Learning in Communication Sciences \& Disorders: Vol. 4: Iss. 3, Article 1.

DOI: https://doi.org/10.30707/TLCSD4.3/BWHV6573

Available at: https://ir.library.illinoisstate.edu/tlcsd/vol4/iss3/1 
Simucase: Embrace the Power of Simulation-Based Learning 
et al.: Simucase: Embrace the Power of Simulation-Based Learning

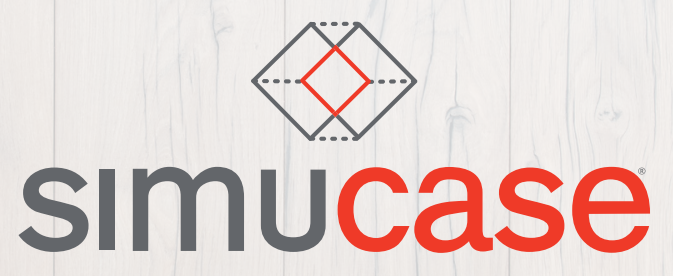

EMBRACE THE POWER of simulation-based learning

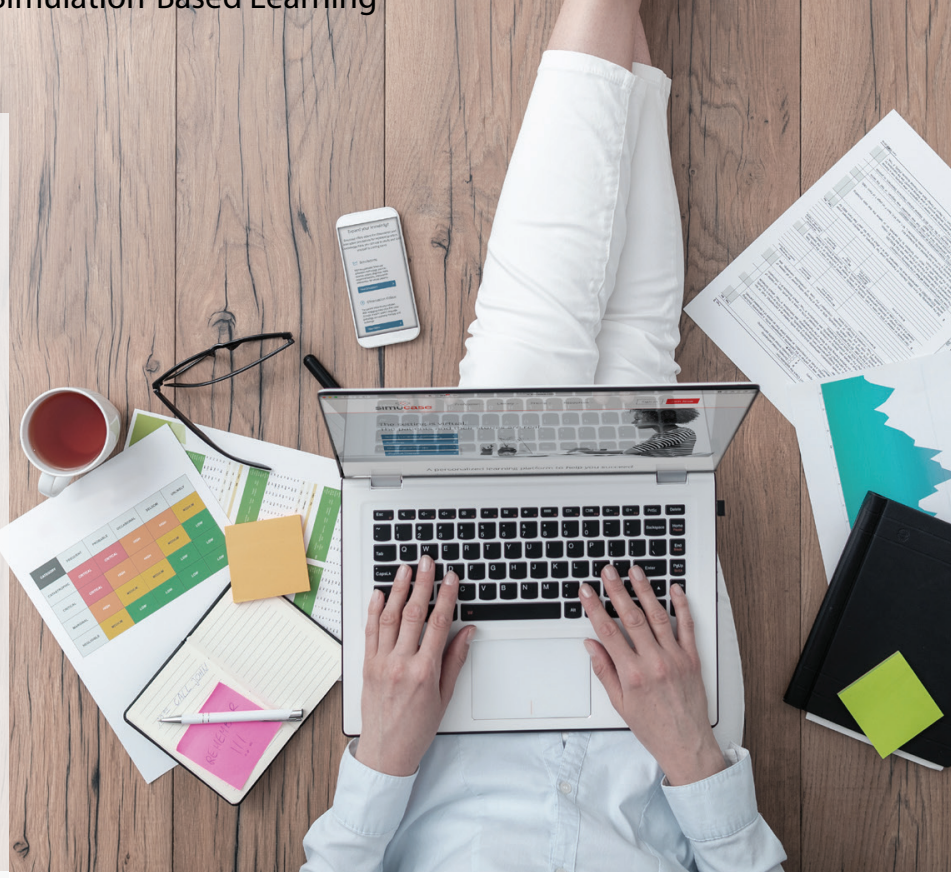

\section{Our professions include speech-language pathology + audiology!}

The premiere solution for simulation-based education, Simucase offers 24/7 access so members can build their clinical skills and earn observation/clinical clock hours anytime.*

Simucase is a competency-based learning platform that combines the power of simulation-based learning with a comprehensive patient video library! The library is always growing and includes simulations and patient videos in the fields of audiology, speech-language pathology, occupational therapy, and physical therapy.

\section{LEARN MORE: simucase.com/TLCSD2020}

Try Simucase FREE for 10 days!

Promo Code: TLCSD2020

\section{Contact Us}

Get a quote or schedule a demo sales@simucase.com

Submit content + help us grow the library editorial@simucase.com 